\title{
Anodic Dissolution of Cu-Zn-Ni Alloy Scraps in Copper(II) sulphate solution
}

\author{
Zuxuan $W u^{1,2,3}$, Lei Li ${ }^{1,2,3, *}$, Jiayun Wang ${ }^{2,3}, Y u W^{2} g^{2,3}$ \\ ${ }^{1}$ State Key Laboratory of Complex Non-ferrous Metal Resources Clean Utilization, Kunming \\ University of Science and Technology, Kunming 650093, China. \\ ${ }^{2}$ Engineering Research Center of Metallurgical Energy Conservation and Emission Reduction of \\ Ministry of Education, Kunming University of Science and Technology, Kunming 650093, China. \\ ${ }^{3}$ Faculty of Metallurgical and Energy Engineering, Kunming University of Science and Technology, \\ Kunming 650093, China. \\ *E-mail: tianxiametal1008@163.com
}

doi: $10.20964 / 2019.12 .32$

Received: 2 August 2019 / Accepted: 4 September 2019 / Published: 29 October 2019

In this work, the anodic dissolution properties of $\mathrm{Cu}-\mathrm{Zn}-\mathrm{Ni}$ alloy scraps in $45 \mathrm{~g} \mathrm{~L}^{-1} \mathrm{CuSO}_{4}$ solutions have been analyzed. The analysis methods employed were potentiodynamic polarization techniques, electrochemical impedance spectroscopy and electron probe microscopic analysis. In a certain range, the anodic dissolution of the $\mathrm{Cu}-\mathrm{Zn}-\mathrm{Ni}$ alloy scraps in $\mathrm{CuSO}_{4}$ solutions increased with the $\mathrm{H}_{2} \mathrm{SO}_{4}$ concentration and temperature. The overall dissolution of the $\mathrm{Cu}-\mathrm{Zn}-\mathrm{Ni}$ alloy scraps were found to be under anodic control; further, the anodic dissolution process was under diffusion control deduced from the activation energy of the anode dissolution process being $14.6 \mathrm{~kJ} \mathrm{~mol}^{-1}$. After heat treating the alloy scraps, the $\mathrm{Cu}-\mathrm{Zn}-\mathrm{Ni}$ alloy scraps were found to be more susceptible to dissolution due to the increase of the size of the grains and the decrease of the particle size uniformity.

Keywords: $\mathrm{Cu}-\mathrm{Zn}-\mathrm{Ni}$ alloy scraps; $\mathrm{CuSO}_{4}$ solutions; anode dissolution; heat treatment; resource recycling

\section{$\underline{\text { FULL TEXT }}$}

(C) 2019 The Authors. Published by ESG (www.electrochemsci.org). This article is an open access article distributed under the terms and conditions of the Creative Commons Attribution license (http://creativecommons.org/licenses/by/4.0/). 